\title{
EFEKTIVITAS PELATIHAN METODE CERAMAH DAN DISKUSI KADER KESEHATAN UNTUK MENINGKATKAN PENGETAHUAN TENTANG KESEHATAN IBU DAN ANAK DI PUSKESMAS I BATURRADEN
}

\author{
EFFECTIVENESS OF HEALTH CADRE TRAINING METHODS \\ LECTURE AND DISCUSSION TO INCREASE KNOWLEDGE ABOUT \\ MATERNAL AND CHILD HEALTH IN BATURRADEN I COMMUNITY \\ HEALTH CENTER
}

\author{
Arif Kurniawan, Elviera Gamelia, Colti Sistiarani \\ Jurusan Kesehatan Masyarakat Fakultas Ilmu-Ilmu Kesehatan \\ Universitas Jenderal Soedirman
}

\begin{abstract}
ABSTRAK
Masalah kesehatan ibu dan anak merupakan masalah utama pedesaan di pusat kesehatan masyarakat I Baturaden, kecamatan Banyumas. Masyarakat pedesaan di wilayah ini tidak memiliki akses terhadap informasi kesehatan ibu dan anak yang memadai, dan kurangnya informasi kesehatan saat ini. Penelitian ini bertujuan untuk mengetahui efektifitas pelatihan melalui perkuliahan dan diskusi tentang peningkatan pengetahuan tenaga kesehatan tentang kesehatan ibu dan anak. Penelitian ini merupakan penelitian eksperimental kuasi dengan sampel 30 penomoran kader kesehatan. Analisis data yang digunakan dalam penelitian ini adalah uji t berpasangan untuk menguji perbedaan pengetahuan sebelum dan sesudah intervensi. Hasilnya menunjukkan nilai rata-rata pengetahuan tentang kesehatan ibu dan anak sebelum pelatihan $(9,31)$ dan setelah pelatihan (10.0). Hasilnya menunjukkan nilai rata-rata pengetahuan tentang promosi kesehatan ibu dan anak sebelum pelatihan (3.31) dan setelah pelatihan (5.58). Hasil statistik menunjukkan tidak ada perbedaan dalam peningkatan pengetahuan tentang kesehatan anak ibu, pengetahuan promosi kesehatan ibu dan anak sebelum dan sesudah intervensi. Saran yang diberikan adalah pelatihan lanjutan pendidikan promotor kesehatan pada petugas kesehatan dengan metode simulasi dan pendampingan.

Kata Kunci : Ceramah, diskusi, Kesehatan Anak Ibu
\end{abstract}

\begin{abstract}
Maternal and child health problems is a major problem in rural of Baturaden I public health centers,Banyumas disctrict. Rural communities in the region have no access to maternal and child health information that is adequate, and the present lack of health information. This study aims to determine the effectiveness of training through lecture and discussion on the improvement of health worker knowledge about maternal and child health. This research is a quasi experimental study with a sample of 30 health cadres numbering. Analysis of the data used in this study is the paired $\mathrm{t}$ test to test for differences in knowledge before and after the intervention. The results showed an average value of knowledge about maternal and child health before training (9.31) and after training ( 10.0 ). The results showed an average value of knowledge about maternal and child health promotion before training (3.31) and after training ( 5.58 ). The statistical results showed no difference in the increase in knowledge about maternal child health, maternal and child health promotion knowledge before and after the intervention. Advice given is the advanced training of health promoters education on health workers with the method of simulation and mentoring..

Key words : Lecture, discussion, Maternal Child Health
\end{abstract}




\section{A. Pendahuluan}

$$
\begin{aligned}
& \text { Permasalahan kesehatan } \\
& \text { ibu dan anak merupakan } \\
& \text { masalah utama di perdesaan di } \\
& \text { wilayah Puskesmas I Baturaden } \\
& \text { Kabupaten Banyumas. } \\
& \text { Masyarakat perdesaan di } \\
& \text { wilayah tersebut tidak } \\
& \text { mempunyai akses informasi } \\
& \text { kesehatan ibu dan anak yang } \\
& \text { memadai, dan rendahnya } \\
& \text { kekinian informasi kesehatan. } \\
& \text { Poliklinik Kesehatan Desa di } \\
& \text { wilayah perdesaan Puskesmas I } \\
& \text { Baturraden hanya berfungsi } \\
& \text { pusat pemeriksaan kesehatan } \\
& \text { dasar bagi masyarakat, namun } \\
& \text { belum dikembangkan sebagai } \\
& \text { pusat pengembangan media } \\
& \text { promosi kesehatan perdesaan. } \\
& \text { Desa di wilayah Puskesmas I } \\
& \text { Baturaden memiliki potensi } \\
& \text { kader kesehatan yang aktif, dan } \\
& \text { terbuka dalam menerima } \\
& \text { informasi kesehatan dari } \\
& \text { perguruan tinggi. Perumusan } \\
& \text { masalah yang ada dalam } \\
& \text { penelitian ini adalah apakah } \\
& \text { pelatihan kader kesehatan } \\
& \text { melalui metode ceramah dan } \\
& \text { diskusi efektif dalam } \\
& \text { meningkatkan pengetahuan }
\end{aligned}
$$

tentang kesehatan ibu anak serta promosi kesehatan ibu anak di wilayah kerja Puskesmas I Baturaden.

\section{B. Metodologi}

Penelitian ini merupakan penelitian quasi eksperimental dengan melalukan intervensi pelatihan kader kesehatan dengan metode ceramah dan diskusi. Variabel penelitian yang diukur melalui pre test dan post test adalah pengetahuan kader kesehatan tentang kesehatan ibu anak dan promosi kesehatan ibu anak. Sampel penelitian ini adalah kader kesehatan di wilayah kerja Puskesmas Baturaden I sejumlah 30 orang. Analisa data penelitian ini menggunakan analisis deskriptif hasil pre test dan post test, serta analisis paired t-test untuk menguji perbedaan hasil pre test dan post test.

\section{Hasil dan Pembahasan}

1. Analisis Univariat

Hasil pre test dan post test tentang pengetahuan kader kesehatan mengenai kesehatan ibu dan anak sebagai berikut : 
Tabel 1. Hasil pre test dan post test tentang pengetahuan kader kesehatan mengenai kesehatan ibu dan anak dengan metode ceramah

\begin{tabular}{|c|c|c|c|c|c|}
\hline No & Kegiatan & Materi & Minimum & Maximum & Mean \\
\hline 1. & Pre Test & $\begin{array}{l}\text { Kesehatan ibu dan } \\
\text { anak }\end{array}$ & 9 & 10 & 9,31 \\
\hline 2 & Post Test & $\begin{array}{l}\text { Kesehatan ibu dan } \\
\text { anak }\end{array}$ & 10 & 10 & 10 \\
\hline
\end{tabular}

Hasil pre test diatas rata-rata pengetahuan

menunjukkan bahwa nilai rata-

rata pengetahuan responden

tentang kesehatan ibu dan anak

yaitu 9,31. Hasil post test

menunjukkan bahwa nilai

pengetahuan responden tentang

kesehatan ibu dan anak yaitu

10. Hal ini menunjukkan secara

desktiptif ada peningkatan nilai responden tentang kesehatan

ibu dan anak sebesar 0,69.

Hasil pre test dan post test tentang pengetahuan kader kesehatan mengenai promosi kesehatan ibu dan anak dengan metode diskusi sebagai berikut :

Tabel 2. Hasil pre test tentang pengetahuan kader kesehatan mengenai promosi kesehatan ibu dan anak.

\begin{tabular}{lclccc}
\hline No & Kegiatan & \multicolumn{1}{c}{ Materi } & Minimum & Maximum & Mean \\
\hline 1. & Pre Test & Promosi kesehatan & 2 & 5 & 3,31 \\
& & & & \\
& & & & \\
& & perpustakaan PKD anak melalui & & \\
\hline 2 & Post Test & Promosi Kesehatan & 4 & 7 & \\
& & ibu dan anak melalui \\
& & & & \\
\hline
\end{tabular}

Hasil pre test diatas yaitu 3,31. Hasil post test diatas menunjukkan bahwa nilai ratamenunjukkan bahwa nilai ratarata pengetahuan peserta tentang rata pengetahuan peserta tentang pengelolaan perpustakaan kesehatan di Poliklinik pengelolaan perpustakaan Kesehatan Desa masih rendah kesehatan di Poliklinik Kesehatan Desa adalah 5,85. Hal 
ini menunjukkan bahwa ada

Poliklinik Kesehatan Desa

peningkatan rata-rata belum optimal.

pengetahuan peserta dari nilai

3,13 menjadi 5,85. Hasil yang

2. Analisis Bivariat

dicapai untuk pengetahuan

Hasil analisis bivariat peserta tentang promosi tentang pengetahuan kader

kesehatan ibu dan anak melalui kesehatan tentang kesehatan ibu pengelolaan perpustakaan di dan anak sebagai berikut :

Tabel 3. Hasil Uji Beda Nilai Pre Test - Post Test Tentang Pengetahuan Kader Kesehatan Mengenai Kesehatan Ibu dan Anak

\begin{tabular}{llccl}
\hline No & $\begin{array}{l}\text { Paired Sampel test } \\
\text { Pre test }- \text { post test }\end{array}$ & t & df & Sign (2-tailed) \\
& & & & \\
\hline 1 & Kesehatan ibu dan anak & 5,196 & 12 & 0,0001 \\
\hline
\end{tabular}

Hasil uji beda dengan menunjukkan bahwa menggunakan uji statistik Paired penyuluhan dengan metode $\mathrm{t}$ test menunjukkan ada beda ceramah dan diskusi kelompok antara hasil pre test dan post test dapat meningkatkan tentang kesehatan ibu dan anak dengan nilai $\mathrm{p}$ value nya adalah $0,0001<0,05$, sehingga jawaban hipotesisnya adalah ada beda antara pre dan post test materi kesehatan ibu dan anak. Hasil uji statistik tersebut menunjukkan efektifitas refreshing kader tentang kesehatan ibu dan anak sudah baik.

Hasil penelitian Tarigan (2010) tentang efektivitas ceramah dan diskusi kelompok terhadap pengetahuan kesehatan reproduksi pada remaja pengetahuan dan sikap remaja tentang kesehatan reproduksi pada remaja di Yayasan Pendidikan Harapan Mekar Medan Tahun 2010.

Hasil penelitian yang dilakukan oleh Helmi dan Paramastri (1998) menunjukkan bahwa metode yang paling efektif bagi orang tua dalam meningkatkan pengetahuan perilaku seksual sehat secara berurutan adalah ceramah, diskusi kelompok dan brosur. Berdasarkan penelitian ini 
menunjukkan metode pelatihan kader kesehatan yang digunakan untuk intervensi sudah tepat yaitu menggunakan ceramah dan diskusi , karena sebagian besar responden adalah orang tua.

Hasil penelitian Sarwani (2014) tentang efektifitas ceramah terhadap pengetahuan kader kesehatan tentang penyakit talasemia menunjukkan adanya perbedaan pengetahuan sebelum dan sesudah kegiatan ceramah, rata-rata skor pengetahuan sebelum ceramah 10,82 meningkat menjadi 12,18. Penelitian Hirawati (2014) menunjukkan bahwa ada perbedaan yang signifikan pengetahuan remaja putri tentang kebersihan alat genetalia sebelum dan sesudah diberikan pendidikan kesehatan metode ceramah, p-value $0,000<\alpha$ $(0,05)$, dan menunjukkan bahwa tidak ada perbedaan yang signifikan pengetahuan remaja putri tentang kebersihan alat genetalia sebelum dan sesudah diberikan pendidikan kesehatan metode diskusi kelompok dengan p-value $0,277<\alpha(0,05)$.
Penelitian

Chandrashekhar menujukkan efektivitas sesi pendidikan kesehatan dalam meningkatkan pengetahuan tentang praktik menyusui di antara perempuan pasca-natal. Intervensi yang melibatkan pendidikan kesehatan sebagai intervensi yang dilakukan melalui bantuan audio visual dan metode ceramah. Pengetahuan itu dinilai sebagai pre-test dan post-test dengan menggunakan kuesioner prestructured melalui metode wawancara. Efektivitas dinilai melalui peningkatan skor post test dibandingkan dengan skor pre-test. Hasil: Studi menunjukkan bahwa ada perbedaan yang signifikan $(\mathrm{p}=$ $0,000)$ antara skor rata-rata tes pengetahuan pra $(14,25)$ dan post test pengetahuan $(18,40)$. skor pre-test berkisar 8-17 sedangkan skor post-test berkisar antara 15 sampai 20. Hasil penelitian menyimpulkan pendidikan kesehatan efektif dalam meningkatkan pengetahuan tentang praktik 
menyusui di antara para wanita setelah melahirkan.

Penelitian Keikhaee

(2014) menunjukkan pengaruh pendidikan gigi dan mulut oleh rekan-rekan pengetahuan dan perilaku kelas satu siswa perempuan di Zabul, Iran dengan studi kuasieksperimental ini dilakukan pada tahun 2012, 287 siswa SD perempuan dipilih secara acak dan belajar di Zabul. Pre-test dan post-test dilakukan dengan menyelesaikan kuesioner yang dirancang untuk menilai pengetahuan dan perilaku menyikat gigi dan menggunakan sodium fluoride obat kumur. Hasil penelitian menunjukkan

Tabel 4. Hasil Uji Beda Nilai Pre Test - Post Test Tentang Pengetahuan Kader Mengenai Promosi Kesehatan Ibu dan Anak

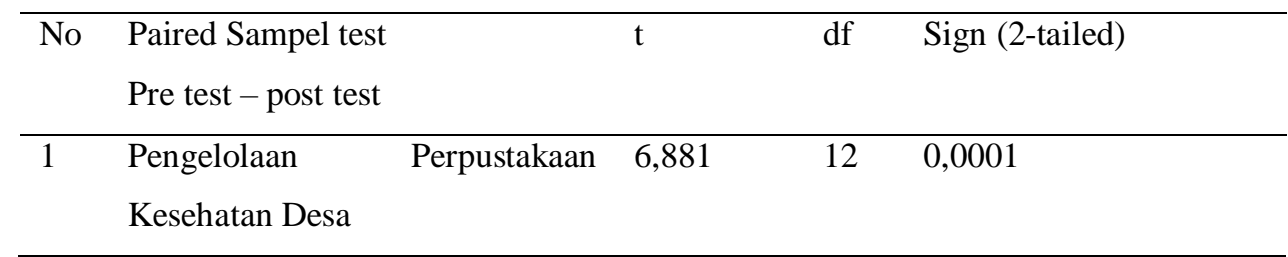

Hasil uji beda dengan value nya adalah $0,0001<0,05$, menggunakan uji statistik Paired $\mathrm{t}$ test menunjukkan ada beda antara hasil pre test dan post test tentang pengelolaan perpustakaan dengan nilai $p$ ada perbedaan yang signifikan antara nilai rata-rata dari dua kelompok dalam pengetahuan dan perilaku setelah pendidikan, sehingga skor rata-rata pengetahuan dan perilaku siswa yang dididik oleh rekan-rekan yang lebih tinggi dari mereka sebelum pendidikan $(\mathrm{P}<0,001)$. pendidikan gigi dan mulut siswa dengan teman sebaya adalah metode sederhana, murah, dan oleh sistem kesehatan.

Hasil analisis bivariat tentang pengetahuan kader kesehatan mengenai promosi kesehatan ibu dan anak sebagai berikut : efektif yang dapat digunakan 
pelatihan

pengelolaan

perpustakaan sudah baik.

Namun Pencapaian pengetahuan

kader dalam mengelola

perpustakaan belum optimal.

Hasil penelitian ini sesuai dengan penelitian Lubis (2013) bahwa terdapat peningkatan pengetahuan dan sikap pada responden tentang PHBS akibat dari intervensi melalui penyuluhan dengan metode diskusi di Sekolah Dasar Negeri Kelurahan Namogajah Kecamatan Medan Tuntungan.

Hasil penelitian ini sesuai dengan penelitian Widyaningsih (2009) bahwa pendidikan gizi dengan metode diskusi kelompok dan ceramah dapat meningkatkan pengetahuan dan sikap mengenai anemia gizi besi remaja putri. Metode diskusi kelompok sama efektif dengan metode ceramah dalam meningkatkan pengetahuan dan sikap mengenai anemia gizi pada remaja putri.

Hasil penelitian Husodo dan Widagdo (2008) tentang pengetahuan dan sikap konselor
SMP dan SMA dalam penyuluhan kesehatan reproduksi di kota semarang menunjukkan adanya peningkatan pengetahuan $(\mathrm{p}=$ 0,003) dan sikap $(\mathrm{p}=0,001)$ pada konselor SMP. Hasil penelitian juga menunjukkan adanya peningkatan pengetahuan $(\mathrm{p}=0,0095)$ dan sikap $(\mathrm{p}=0,0095)$ sesudah penyuluhan pada konselor SMA.

Penelitian Mullany (2006) menunjukkan keterlibatan lakilaki dalam intervensi kesehatan reproduksi dapat meningkatkan hasil kesehatan positif. Sebuah uji coba terkontrol secara acak dirancang untuk menguji dampak yang melibatkan pasangan pria dalam pendidikan kesehatan antenatal pada pemanfaatan pelayanan kesehatan ibu dan kesiapan lahir di Nepal perkotaan. Intervensi pendidikan terdiri dari dua sesi pendidikan kesehatan 35-min. Perempuan diikuti sampai setelah melahirkan. Wanita yang menerima pendidikan dengan 
suami lebih mungkin untuk menghadiri kunjungan postpartum dibandingkan perempuan yang menerima pendidikan saja $[\mathrm{RR}=1,25$, $95 \% \mathrm{CI}=(1,01,1,54)]$ atau tidak ada pendidikan $[\mathrm{RR}=$ $1,29,95 \% \mathrm{CI}=(1,04,1,60)]$. Wanita yang menerima pendidikan dengan suami mereka juga hampir dua kali lebih mungkin sebagai perempuan kelompok kontrol melaporkan persiapan pembuatan> 3 lahir $[R R=1,99$, $95 \% \quad \mathrm{CI}=(1.10,3.59)]$. kelompok belajar yang sama sehubungan dengan menghadiri jumlah yang direkomendasikan dari pemeriksaan perawatan antenatal, melahirkan di lembaga kesehatan atau memiliki penyedia terampil saat lahir. Data ini memberikan bukti bahwa mendidik perempuan hamil dan pasangan pria mereka menghasilkan dampak bersih lebih besar pada perilaku kesehatan ibu dibandingkan dengan mendidik perempuan saja.
Hasil

penelitian Novrianda (2015) menunjukkan terdapat perbedaan efektivitas pendidikan kesehatan antara Puskesmas Padang Pasir dengan Pauh pada kemampuan merawat $\quad(p=0,004) . \quad$ Oleh karena itu pendidikan kesehatan tentang ISPA dengan media yang lebih menarik seperti booklet perlu diberikan terutama pada ibu untuk meningkatkan pengetahuan dan kemampuan merawat balita dengan ISPA.

Hasil penelitian Sakiyah (2015) menunjukkan ada perbedaan pengetahuan responden antara sebelum dan sesudah dilakukan pendidikan kesehatan dengan metode diskusi dengan $\mathrm{p}$ value 0,001 dan ada perbedaan pengetahuan responden antara sebelum dan sesudah dilakukan pendidikan kesehatan dengan metode ceramah dengan $\mathrm{p}$ value 0,001 . Hasil penelitian ini juga menunjukkan tidak ada perbedaan yang signifikan antara metode diskusi dan metode ceramah. 
Hasil

Kurniawan

penelitian

menunjukkan pelatihan peer

educator gizi buruk telah

mampu

meningkatkan

pengetahuan responden tentang

teknik peer education dan penanggulangan gizi buruk.

Ada perbedaan signifikan

tingkat pengetahuan responden

sebelum dan sesudah intervensi

tentang dan teknik peer

education dan teknik

penanggulangan gizi buruk.

Hasil penelitian ini

menunjukkan peningkatan

kemampuan kader kesehatan

untuk dapat mentransfer

informasi kesehatan tentang

kesehatan ibu dan anak kepada

masyarakat. Kemampuan kader

kesehatan dapat ditingkatkan

melalui pelatihan "peer

educator" terutama kemampuan

kader sebagai motivator,

kemampuan kader sebagai

komunikan tentang kesehatan

ibu dan anak. Pola yang

seharusnya dikembangkan lebih

lanjut adalah setelah kader

kesehatan di berikan pelatihan,

kemudian

dilakukan pendampingan oleh tim

pengabdian untuk

mempraktekkan kemampuan

kader kesehatan dalam

mengkomunikasikan materi

kesehatan ibu dan anak kepada

ibu-ibu melalui pertemuan dasa

wisma, kelompok belajar

khusus, dan atau saat pelayanan

PKD.

\section{Kesimpulan dan Saran}

1. Kesimpulan

a. Pelatihan kader kesehatan dengan metode ceramah dan diskusi mampu meningkatkan

pengetahuan kader kesehatan mengenai kesehatan ibu dan anak di wilayah Puskesmas Baturaden I.

b. Pelatihan kader kesehatan dengan metode ceramah dan diskusi mampu meningkatkan

pengetahuan kader kesehatan mengenai promosi kesehatan ibu dan anak melalui pengelolaan perpustakaan di Poliklinik Kesehatan Desa.

2. Saran 


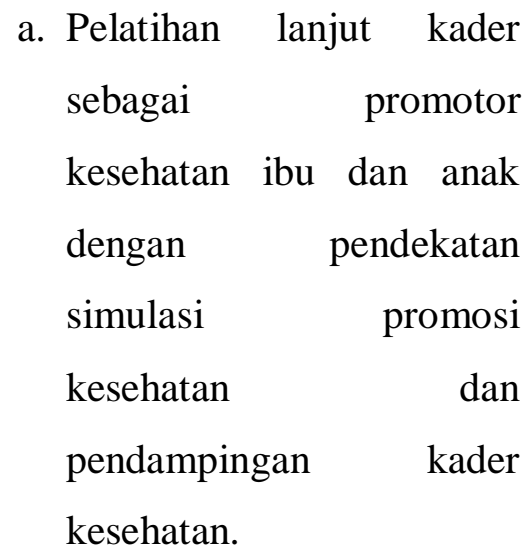

\section{G. Daftar Pustaka}

Chandrashekhar R, Basagoudar S, and Muneshwar S, Effectiveness Of Health Education On Increasing Knowledge About Breast Feeding Practices Among Post-Natal Women, International Journal of Current Research and Review (IJCRR), 2012 : 4 (24) : 113-118

Helmi FA dan Paramastri A, 1998, Efektivitas Pendidikan Seksual Dini Dalam Meningkatkan Pengetahuan Perilaku Seksual Sehat, Jurnal Psikologi, N0 2, Hal 25 - 34, Universitas Gadjah Mada.
Hirawati H.P, Masruroh, dan Triwijayanti Y.O, Pengaruh Pendidikan Kesehatan Menggunakan Metode Ceramah dan Diskusi Kelompok Terhadap Peningkatan Pengetahuan remaja Putri Tentang Kebersihan Alat Genetalia di SMA Negeri I Ungaran, Jurnal Keperawatan Maternitas, Vol 2 No 2 Nov 2014, Hal 90-97

\section{Husodo TB dan Widagdo L, Pengetahuan dan Sikap Konselor SMP dan SMA Dalam Penyuluhan Kesehatan Reproduksi di Kota Semarang, Jurnal Makara Kesehatan, Vol 12, No 2 Desember 2008.}

Keikhaee R, Rakhshani F, Fijan S, Keikhaee M, Rad JS, Roostaee
F. The Effectiveness of Oral Health Education by Peers On Knowledge and Performance of Student in Zabol, Iran. Int J res Med Sci. 2014 ;2 (1): 222227

Kurniawan A, dan Gamelia E, Efektifitas Pelatihan Pencegahan Gizi Buruk Balita Pada Peer education untuk meningkatkan pengetahuan kelompok Dasawisma di Puskesmas Baturraden I, Jurnal Kesmas Indonesia, Vol 7 No 2 januari 2015.

Lubis AZ, Lubis LN, dan Syahrial E, Pengaruh Penyuluhan dengan Metode Ceramah dan Diskusi Terhadap Peningkatan Pengetahuan dan Sikap Anak Tentang PHBS di Sekolah Dasar Negeri 065014 Kelurahan Namogajah Kecamatan Medan Tuntungan Tahun 2013, Skripsi, Tidak Dipublikasikan

Mullany C.B, Becker S and Hindin MJ, The Impact of Including Husbands In Antenatal Health Education Services On Maternal Health Practices In Urban Nepal : Results From A Randmized Controlled Trial, Health Educational Research, Volume 22 Issue 2 PP. 166176

Novrianda D, Lucida H, dan Soumariris I, Perbandingan Efektivitas Pendidikan Kesehatan Terhadap Pengetahuan dan Kemampuan Ibu Merawat Balita ISPA di Puskesmas Padang Pasir dan Pauh, Jurnal Sains Farmasi dan Klinis Vol 01 No 02 Mei 2015.

R. Chandrashekhar, Basagoudar S, and Muneshwar S, Effectiveness Of Health Education On Increasing Knowledge About Breast Feeding Practices Among Post-Natal Women, International Journal Of Current Research and Review (IJCRR), 2012 : 4 (24) : 113-118 
Sakiyah M, Jaji, Muharyani, P.W, Perbedaan Efektivitas Metode Diskusi dan Ceramah Terhadap Pengetahuan Pekerja Tentang Alat Pelindung Diri (APD) di Bengkel Las kelurahan Bukit Lama Palembang, Jurnal Keperawatan Sriwijaya Vol 2 No 2 Juli 2015.

Sarwani SR, Nurhayati, dan Supriyanto, Efektifitas Ceramah Terhadap Pengetahuan Kader Kesehatan Tentang Penyakit Talasemia di Kecamatan Pekuncen dan Kecamatan Sumbang Kabupaten Banyumas, Jurnal Kesmas Vol 8. No 1, Maret 2014.
Tarigan SPA, 2010, Efektivitas Metode Ceramah dan Diskusi Kelompok Terhadap Pengetahuan dan Sikap Tentang Kesehatan Reproduksi Pada Remaja di Yayasan Pendidikan Harapan Mekar Medan, Tesis, Fakultas Kesehatan Masyarakat Universitas Sumatera Utara, Tidak Dipublikasikan

Widyaningsih I, dan Susiloretni AK, Efektifitas Metode Ceramah dan Diskusi Kelompok Untuk Meningkatkan Pengetahuan dan Sikap Remaja Putri tentang Anemia Gizi Besi di SMA Negeri 2 Semarang, Skripsi, Tidak Dipublikasikan 